\title{
Signing and Signifyin': Negotiating Deaf and African American Identities ${ }^{1}$ Heather D. Clark University of Washington
}

For individuals who are both African American and Deaf finding a place to belong is a process of navigating their many cultural identities. In this paper I explore the following questions: where do individuals who are African American and Deaf find and make community? To which communities do they perceive they belong? Is their primary identity African American, Deaf or something else? Does belonging to one community negate membership in another? Does the presence of African American Deaf individuals have an impact on either community or are they forced to create an entirely new one for themselves?

Currently there is a growing body of literature on global Deaf communities from the formation of new sign languages in Nicaragua and Israel to the creation of cohesive Deaf communities around the world (Monaghan et al 2003; Sandler et al 2005). These recent studies shed light on how communities around the world are navigating their multiple racial/ethnic, cultural and communicative identities. However, there has been little focus on the African American Deaf community. While there has been some research conducted in regard to the sociolinguistic aspect of American Sign Language (ASL) use in the African American Deaf community (Woodward 1976; Maxwell \& Smith-Todd 1986; Aramburo 1989; Lucas 1995; Lewis 1997), there has been no research conducted regarding the identity formation, cultural identification and navigation of individuals who are both African American and Deaf in the Northwest of the United States.

\section{Definitions}

Like in many marginalized communities labeling oneself is an important step in creating group solidarity. In this paper I am defining African American/Black as individuals who were bom in the United States, have African ancestry, and self identify as African American or Black. I will be using the two terms interchangeably throughout this paper.

When refering to dDeaf people there are two different ways in defining a member of the community. In writing one distinction is made with a lower case ' $\mathrm{d}$ ' and the other is made with a capital ' $D$ '

The lower case 'd' distinction refers to an individual's physical ability of not being able to hear. One who identifies this way usually does not use ASL as a primary mode of

\footnotetext{
${ }^{1}$ An earlier vasion of this paper was presented at the $34^{\text {th }}$ Annual National Association for Ethnic Studies conference in San Francisco, CA. This paper was included in a panel titled, "Shifling Perspectives, Shifting Lives: Multiple Identities". I would like to thank Laada Bilainuk for her assistance with editing and revising the many drafts of this paper to help me get to this point. Funding for this research is from the National Science Foundation Graduate Research Program.
} 
communication nor do they ascribe to the beliefs of the larger Deaf community. While the capital 'D' Deaf person refers to an individual who cannot hear but is one who uses ASL as a primary mode of communication and participates in the larger community of people who sign and culturally identify as Deaf (Woodward, 1972; Padden \& Humphries, 1988; Senghas \& Monaghan, 2002). The different variations are not only in writing, when signing the distinction is made as well. An individual who identifies as deaf is seen to have more of a hearing ideology therefore they are referred to by the sign "thinks like a hearing person" (which is conveyed with the sign for "hearing" placed on the forehead). An individual who identifies as Deaf is seen to have a culturally Deaf perspective and is referred to with the "strong deaf" or "fluent ASL" signs (Kannapell, 1989). For outsiders this may seem cumbersome or unnecessary; however, for individuals who associate with these labels they are indeed necessary and explain a great deal about a person's perspective and the community in which they belong to. Because I am refening to deafness as a cultural attribute I will be using the capital 'D' Deaf definition throughout this paper.

\section{Community}

When one thinks of community, images come to mind of individuals who have a common history, shared beliefs, and a common language. This is critical for African American and Deaf communities, which historically have both been socially marginalized and are not reflected in mainstream society. Many disciplines have been grappling with the definition of community from anthropology to sociology to psychology. The paramount questions that arise are how communities are formed, what do communities entail, and who can belong to a community. Common interests, race/ethnicity and/or beliefs can form communities; because of this each of us has the potential to belong to many different communities throughout our lifetime. There is the geographical community in which we live, the educational community of the school we attend or the religious community in which we participate. One key parameter in defining community is whether it is defined from inside; members of a community consider themselves a community regardless what others think, or from the outside; people from outside the community label it as such because of the belief that all people having the same characteristic belong to the community. Whether defined from the inside or outside-belief is key-you have to believe that certain characteristics make a community, whether your own or others'. My focus is on community being defined from the inside. Belonging to and participating in a community can also be empowering, it has the potential of being a place where we find others like ourselves who can celebrate and commiserate a common experience.

Language is one way to create cohesiveness within communities either real or imagined and in the Deaf community ASL is a way to create this cohesiveness. Barbara Kannapell asserts, "It is our language in every sense of the word. We create it, we keep it alive, and it keeps us and our traditions alive" (Kannapell, 1989: 26-27). 
What is unique about the African American Deaf person is that they potentially belong to two communities where per formed (oral or signed) language has been the primary tool in constructing and transmitting cultural identity information. Historically African Americans were denied the right to leam to read or write and consequently stories were told as a way of preserving the traditions and sharing the experiences of the community. The Deaf community has gone through periods of time when ASL was prohibited from being used or taught in public schools (Van Cleve \& Crouch, 1989; Lane, Hoffmeister, \& Bahan, 1996); also there is no written form of ASL. As a result for both Deaf people and African Americans stories were the dominant way in which to share cultural information. As linguist Charlotte Linde clearly states, storytelling "can create group membership for [the speaker] and solidarity for [a] group" (Linde, 1993: 114).

\section{African Americans and Language}

Language among African Americans is a fundamental part of who we are as a community: not only does it unite the community but it also distinguishes it from others. For African Americans, verbal language in all its forms, such as playing the dozens or "code switching" from Black English to Mainstream American English are vital in constructing who we are (Hecht, 2003). Communication is an essential aspect of culture, and a shared language is an important vehicle for the familial sharing of love and identity. Stories are told among family and friends whenever there is an occasion to gather. Thus language is a way in which racial and cultural identification is transmitted and history shared As Hecht writes,

"The basic premise of this new theoretical stance is that identity is inherently a communication process and must be understood as a transaction in which messages and values are exchanged. These messages are symbolic linkages between and among people that, at least in part, are enactments of identity. That is, we, as communicators, would like to believe we are simply talking to others; instead, we are also exchanging codes of cultural personhood"'(Hecht, 2003:230).

It is not just what we say, but how we say it that is impoitant. As Peter Burke says, "Speaking the same language, or variety of language, as someone else is a simple and effective way of indicating solidarity" (Burke, 1993:70). He goes on to say that language is "one of the most important of the signs of collective identity" (Burke, 1993:70).

Geneva Smitherman's (1977) asserts the importance verbal language has in the African American community. She highlights the different styles (i.e. folk sayings, songs, stories) as vehicles used to preserve African American heritage and as a way to transmit crucial cultural identity infomation from generation to generation. However, in all of the research there has been no intersection between verbal language use among hearing African Americans and the use of sign language among Deaf African Amcricans as vehicles for the transmission of cultural identity information. 


\section{Deaf Community}

Research has becn conducted regarding the Deaf community and the importance of recognizing ASL as a language (Stokoe, 2001; Monaghan et al 2003) and Deaf people as a cultural minority group (Padden \& Humphries, 1988; Wilcox, 1989; Lane, Hoffmeister, \& Bahan, 1996). ASL is recognized as the vehicle to transmit cultural information in the Deaf community. "American Sign Language has a rich literary tradition. The storyteller and the story have an important role to play in the bonding of the DEAF-WORLD and the transmission of its heritage and accumulated wisdom" (Lane, Hoffimeister, \& Bahan, 1996: 153).

Seattle has a fairly active Deaf community: there are woekly cultural events from Deaf coffee houses to Deaf Blind community classes to interpreted events. Whenever I attend these events I notice that the majority of people in the audience are white. You may sce a few People of Color, but overall it is not a racially/ethnically diverse gathering of people. I am curious to know why this is the case: is it a lack of knowledge of the events, are African American people and, presumably, those of other non-white groups not interested in gathering at these types of events, is it simply because there are not many African American Deaf people in Washington State $^{2}$ or are there other underlying reasons?

To explore these ideas and further develop appropriate questions I interviewed three women friends of mine, Robin, Sherry and Eden ${ }^{3}$. They all identify as Black and Deaf. They are in their early 20's-early 30's and have been active in the Deaf community for some time. I wanted to know their perspective on the mainstream Deaf community and if they felt a part of that community. The general questions I posed to them were how would they characterize the Deaf community and from their experiences do they feel support from it. All three told me that the Deaf community is basically a white community in which they do not feel comfortable being themselves. Robin said, "I don't feel comfortable to express myself in the Deaf community. I feel more comfortable within the African American community." When I asked her to further explain why she felt more comfortable with African American Deaf people she elaborated, "Because they know the slang ${ }^{4}$ I am using, and how we joke with each other. African American people are more expressive, but I have to be careful around white Deaf people." Sherry had a similar perspective: she said, "They don't allow me to be who I am, I am not going to change for you. We have different ways of joking, slang and stories and they do not know them." Eden goes on to say, "I think it kinda depends

\footnotetext{
2 The African American deaf population in Washington State is estimated to be approximately 2000. I was given this estimate by the fomner president of the Washington State chapter of the National Black Deaf Advocates. However, this estimate includes both individuals who were bom deaf or have lost their hearing due to old age.

${ }^{3}$ All names have been changed.

${ }^{4}$ Linguistically the term slang refers to using a particular word choice; however, those I spoke with were clear that how they define slang was more than the werd choice it was how they executed the sign as well.
} 


\section{Clark - Signing and Signifyin'}

on who you are around. . . for the Deaf white person I sign more formal English style of ASL. But with Black people I can use more [informal] ASL, more expressions." Again the notion of negotiating comes into play: these particular women felt if they wanted to interact with the mainstream Deaf community they could not be as expressive as they could be with other African Amcrican Deaf people. They felt as if they would not be accepted in the mainstream Deaf community if they communicated the way that felt most comfortable to them. In essence they felt as if they had to code switch from their African American style of signing to the mainstream style of ASL to be accepted.

Code switching can be defined as, "the use of two or more languages in one speech exchange by bi- or multilingual speakers" (Bailey, 2000:241). An individual may choose to use a more informal speaking register with members of the community to which she belongs. However, in other situations she may change her register to one that reflects the language being used by the majority of others as a way to be accepted. Code switching is not a new concept for African Americans. Research has been done regarding the shifting in language from Mainstream English to African American English Vemacular in certain situations, for certain reasons. My interviews reveal that code switching is present in the Deaf community as well. I asked my interviewees for examples of slang they would use among themselves but not necessarily in the mainstream Deaf community. One such example they shared with me was the difference between the mainstream ASL sign for GIRL and the African American Vernacular English style of GIRL. In mainstream ASL the sign is made with a closed fist with thumb extended upward, stroked downward from cheek to lower jaw. When I was shown the altemative version to GIRL it looked dramatically different. There was the same closed fist and movement down the side of the cheek, however; the body shifted to one side, the shoulders rotated and the head was slightly tilted to an angle. This sign for GIRL is used similarly to the term of solidarity in the hearing African American community, in the example of "you go girl!" I am hoping to explore further the notion of slang usod in the African American Deaf community to find out if it is simply a signed version of hearing African American vemacular and follows its rules, or a completely different vernacular based on American Sign Language that follows its grammatical structure.

Another question I asked my participants was do they feel support from the Deaf community to be African American. Once again the answer I heard was a resounding, "no". Sherry said, "You will be accepted if they [African American Deaf persons] do what the white Deaf community says. If I speak my opinion and they do not agree they will reject me. But if I agree with them they will accept me... I have really only stepped in the [white] Deaf community because of that, I am not totally IN the [white] Deaf community. Robin said, "I feel like they support the others in the community like gay/lesbian, Deafblind, Asian but not African Americans. It is as if you have to educate them about yourself." Both of these women recognize the limitations they have in the Deaf community-even though they have langrage in common there was still something missing, Sherry said, "They don't allow me 


\section{Ethnic Studies Review Volume 30: 1\&2}

to be who I am". Eden expresses a similar sentiment, "The only thing I have in common with the Deaf community is language, that's all." Given the fact that ASL is seen by most as what unites the Deaf community I wanted Eden to elaborate: was there something more than actual langrage, in her mind, needed to unify the community. If she used the same language as the mainstrearn Deaf community, what else was needed to feel a part of the community? She said, 'I'm not myself, I don't feel comfortable signing, because. . .I feel like they always try to control things and they think whoa Black Deaf [people] have an attitude and they mistake my signing, but that's who I am. So I try to sign more proper, I know I should be myself. Keep it real." All three of the women I interviewed spoke to the fact that simply having access to the same language was not a guarantee they would be accepted in the mainstream Deaf community.

One could hope that members of marginalized groups would not recreate the power structure and hierarchies of the mainstream community. However, in my rescarch I have noticed that the belief system of the white Deaf community mimors the attitudes of the dominant culture's negative bias towards African Americans. Many institutions that serve the Deaf community were segregated such as Deaf residential schools in the South and East Coast (Gannon, 1981; Hairston and Smith, 1983; Maxwell and Smith-Todd, 1986), and Deaf social clubs (Hairston \& Smith, 1983; Janesick \& Moores, 1992). Gallaudet University and the National Association for the Deaf did not admit African American Deaf people until the 1950's. The mainstream white Deaf community uses deafness as a unifying factor for creating a cohesive community, but some African American Deaf people have not always felt welcome and as a result some have other priorities and deafness most often is not the primary identity marker. For them race/ethnicity at times takes a paramount role in identification and galvanizing, because of the role race/ethnicity plays in the United States (Aramburo, 1989). As result of the discriminatory practices of the mainstream white Deaf community and the need for African American Deaf people to build community, the National Black Deaf Advocates (with several state chapters) was established in 1982 and is still very active today.

\section{African Americans Embrace Deaf Community}

While many Deaf African Americans do not feel embraced in the mainstream Deaf community these individuals may not feel any more comfortable in the hearing African American community either. In my preliminary research with members of the African American Deaf community in Seattle, it has become evident that for a host of socio-political reasons such as lack of resources to take classes, lack of knowledge about Deaf culture, lack of time needed to learn a new language, hearing family members do not use ASL nor sign with their children. All of them have been raised oral; they read lips and voice for themselves with family members. Robin remembered family gathening and stories being told but was left feeling frustrated because no one was using ASL so she was not able to fully understand what was being said because to lip read multiple conversations at once is impossible. This is 
a common story for many Deaf people who were raised in hearing families with little linguistic communication.

How can hearing African Americans embrace individuals who are Deaf within the community? It is my opinion that first and foremost we have to be able to acknowledge there is an active subculture. Regardless of their audiological abilities - whether they can hear or not they should still be able to be integral members of the African American community. Deaf people of African descent face the same kinds of social discrimination that hearing African Americans do, but even more so-they have a double minority status because of their deafness. For this reason, it is of utmost importance that hearing African Americans find ways to include Deaf African Americans in the greater racial/ethnic community. When I asked Robin how she thought Deaf African Americans could be embraced and better incopporated into the larger African American community she agreed that first the hearing community needs to acknowledge and accept the fact there is a subculture of Deaf African Americans, with a language and culture. She also thought if Deaf people were recognized then the natural extension of this acceptance would be more interpreters made available to facilitate in communication at different cultural and social events. Others have also expressed to me their frustration at not being able to attend cultural events because interpreters were not made available.

Hecht's work clearly illustrates the importance of language and its use for sharing cultural information. He argues that, "Communication and culture are not truly separable. Communication is meaningful because of the culture that frames it, and culture must be expressed to exist" (Hecht, 2003:2). Thus it is vital that hearing families with Deaf children find ways to communicate their family history and their cultural background in a language that is accessible to the Deaf child. For many Deaf people ASL would be the most accessible language; however, what I have leamed from poople I have talked with is that it is unrealistic to suggest that all hearing African American families with Deaf children should leam ASL.

An older African American woman who is audiologically deaf but does not sign nor identify as culturally Deaf explained to me that being Black is already something that sets her apart so placing emphasis on being deaf would further alienate her from family and peers. Because of this perception her family strategically decided to have her leam to voice and read lips, as opposed to having the family leam ASL or embrace the Deaf culture. I understand the attitude that being bom African American in the United States represents one strike against you so why add another strike by identifying as Deaf. I am left wondering where African American Deaf people find a community where they can be their whole self. It is as if they are allowed to be their ethnic self at home with family members but have restricted (limited to lip-reading) access to the language and they can be their more freely communicating cultural self in the Deaf community because they have access to the language, but they feel as if a part of them is missing. 


\section{Ethnic Studies Review Volume 30: 1\&2}

The idea of having to navigate between the mainstream white Deaf community and the hearing African American community is something unique to Seattle. This concept was completely foreign to the African American Deaf people I spoke with in larger cities such as Washington D.C. where there is a larger concentration of African American people in gencral. One woman I spoke with in Washington D.C. felt there was a complete African American Deaf community where she could be herself. There was the same frustration of not having family members sign and the mainstream Deaf community ignoring her racia//ethnic background, but because there were more African American Deaf people as a whole she felt as if she had a consistent community to go to for support. In contrast, in Washington State there are relatively few African Americans, we make up 3.5\% of the state's total population which makes aligning oneself with and finding a community much more of a challenge.

\section{Conclusion}

Thus far in my research it seems that individuals who are both African American and Deaf struggle to align themselves fully with a particular community. Generally hearing African Americans are reluctant to learn ASL, making effective communication with family members nearly impossible. While in the mainstream Deaf community language may be accessible but there are other intangible yet vital aspects of the life experiences of African Americans that are not being expressed I see this study as laying a foundation for other areas of research to be explored between the intersection of African American and Deaf cultural identities. First, how does the relative small African American population in Washington State effect the fostering of an African American Deaf community, in comparison to other states where there are simply more African Americans that can support the many subcultures in the community.

Secondly, regarding language use among this younger group of Deaf African Americans can help us to explore the notion of code switching from an African American style of signing to the mainstream ASL style. Code switching research is common for hearing African Americans but no research has explored this type of code switching in the Deaf community. More research is also needed to find out if the African American signing style is a signed version of a heaning African American vemacular or is it a different style with rules and grammar.

Thirdly, how are individuals who are both African American and Deaf in the Northwest navigating their multiple identities? For the individuals I intervicwed they all seem to understand the limitations of the mainstream Deaf community to fully understand them and how they fit in. They also have accepted the shortcomings of the hearing African American community that has not done much to recognize them as a subculture of the langer African American community or made accommodations for the Deaf African Americans to participate as full members of the community. 
Given that the sample I interviewed are all in their early 20's to early 30 's, I would like to explore if age affects these questions in any way. Do older African American Deaf people face a similar predicament of finding a community to participate in fully? I look forward to continuing work with the various groups involved to understand the dynamics of language and identity.

\section{References:}

Aramburo, A.J. "Sociolinguistic aspects of the Black Deaf Community". In The Sociolinguistics of the Deaf Community. Ed. C. Lucas, New York, NY: Academic Press, 1989. 103-122.

Bailey, Benjamin. “Switching.” Joumal of Linguistic Anthropology 9(1-2) (2000): 241-243.

Gannon, Jack R. Deaf Heritage: A Narrative History of Deaf America. Silver Spring: National Association of the Deaf, 1981.

Hairston, Emest and Linwood Smith. Black and Deaf in American: Are We that Different. Silver Springs: T.J.Publishers, Inc., 1983.

Hecht, Michael L., Ronald L. Jackson II and Sidney A. Ribeau, Eds. African American Communication: Exploring Identity and Culture. Mahwah, NJ: Lawrence Erlbaum Associates, Inc., 2003.

Janesick, Valerie J. and Donald F. Moores. "Ethnic and Cultural Considerations.” Toward Effective Public School Programs for Deaf Students: Context, Process, and Outcomes. Ed. Thomas Kluwin, Donald F. Moores and Martha Gonter Gaustad. New York: Teachers College Press, 1992. 49-65.

Kannapell, Barbara. "Inside the Deaf Community." American Deaf Culture. Ed. Sherman Wilcox. Burtonsville: Linstok Press, 1989.21-28.

Lane, Harlan, Robert Hoffimeister and Ben Bahan, Eds. A Joumey into the DEAFWORLD. San Diego: Dawn Sign Press, 1996.

Linde, Charolette, Life Stories: The Creation of Coherence. New York: Oxford University Press, 1993.

Lucas, C. "Sociolinguistics Vaniation in ASL." In Sociolinguistics in the Deaf Community (Vol 1). Ed. C. Lucas. Washington, D.C.: Gallaudet University Press, 1995. 
Maxwell, M. and S. Smith-Todd. "Black Sign Language and School Integration in Texas." Language in Society 15 (1986): 81-94.

Monaghan, Leila, Karen Nakamura, Constanze Schmaling and Graham H. Tumer. Many Ways to be Deaf: Intemational Variation in Deaf Communities. Washington D.C.: Gallaudet University Press, 2003.

Myers, B. “Gallaudet president-select answers her critics.” The Examiner. Updated May 11, 2006, from http://www.examiner.com/a101429 gallaudet president select answers her critics.html

Padden, Carol and Thomas Humphries. Deaf America: Voices from a Culture. Cambridge, M.A.: Harvard University Press, 1988.

Padden, Carol and Thomas Humphries. Inside Deaf Culture. Cambridge, M.A.: Harvard University Press, 2005.

Sandler, Wendy, Mark Aronoff, Irit Meir and Carol Padden. The Emergence of Grammar: Systemic Structure in a New Language. Proceedings of the National Academy of Sciences of the United States of America. Vol. 102 No. 7 (2005): 2661-2665.

Senghas, Richard J. \& Leila Monaghan, "Sign of Their Times: Deaf Communities and the Culture of Language. Annual Review of Anthropology. 31 (2002): 69-97.

Smitheman, Geneva. Talkin and Testifyin: The Language of Black America. Boston, M.A.: Houghton Mufflin Company, 1977.

Stokoe Jr., William C. Language in Hand: Why Sign Came Before Speech. Washington, DC: Gallaudet University Press, 2001.

Van Cleve, John Vickrey \& Barry A. Crouch. A Place of their Own: Creating the Deaf Community in America. Washington, D.C.: Gallaudet University Press, 1989.

Wilcox, Sheman American DeafCulture. Burtonsville: Linstok Press, 1989.

Woodward, J. 'Implications for sociolinguistic research among the Deaf." Sign Lanquage Studies 1 (1972): 1-7.

Woodward, J. “Black Southem Signing.” Language in Society 5 (1976): 303-311. 